\title{
El estrago individualista y su desorden*
}

\author{
François Dagognet ${ }^{\star \star}$ \\ Traducción del francés al español \\ de Luis Alfonso Palau Castaño \\ DOI: 10.22395/csye.v6n11a15
}

Nos parece que uno de los primeros deberes del filósofo consiste en señalar el mal o sus equivalentes: el desorden, la injusticia, lo intolerable. Antes de combatir al "enemigo", y para combatirlo, apresurémonos a definirlo, y sobre todo a localizarlo.

El mal, según nosotros, no se aloja en el mundo; cuando aquí surgió, se trataba entonces del reverso de un bien; no hay montaña sin valle, según un principio conocido, o también imedalla sin reverso! Leibniz ya lo sostenía con fuerza: "No hay nada inculto, estéril y muerto en el universo; el caos y la confusión son solo aparentes" (Monadología, § 69¹). Jean-Jacques Rousseau iría aún más lejos: en el temblor de tierra de Lisboa (en 1755) discernía no tanto una convulsión o una especie de locura de la tierra como el castigo debido a los hombres que se amontonaban ciegamente en un mismo lugar (las ciudades tentaculares). En una carta a Voltaire del 18 de agosto de 1756, escribía:

No veo que se pueda buscar la fuente del mal moral en otra parte que en el hombre libre, perfeccionado, por tanto corrompido... Creo haber mostrado

Tomado de Dagognet, François (2000). ¿Cómo salvarse de la servidumbre? Justicia, escuela, religión. París: Sanofi - Synthélabo. Capítulo I: El estrago individualista y su desorden. Traducido del francés al español de Luis Alfonso Paláu Castaño, Medellín, abril de 2009. Nota del editor.

** Filósofo, médico y epistemólogo francés nacido en Langres en 1924. Profesor emérito de la Universidad París I. Tuvo como mentor y amigo a Gaston Bachelard, formándose como médico en la Universidad de Estrasburgo con Georges Canguilhem. Sus primeros trabajos se ubican en el ámbito de la objetología al interesarse por el medicamento (partilla, píldora, comprimido o droga como sustancia de viene del exterior y que imita un interior para ser aceptada por el cuerpo enfermo). Se interesó también por las lógicas taxonómicas en las ciencias naturales, además por la imaginología e iconología. Ha escrito sobre espacios como museos, ciudades o fábricas alejándose del narcisismo lengueril de la filosofía. Una fase de su obra la ha dedicado a lo abyecto, lo proscrito, lo sucio o lo grotesco para reflexionar sobre una estética de lo perecedero. Ha reflexionado sobre tres instituciones que definen la visión de mundo occidental: familia, trabajo y nación. Su lectura sobre las superficies lo ha llevado a pensar una moral dinámica entre el adentro y el afuera en el orden del viviente en la búsqueda de las evidencias que se configuran como lenguaje. Entre sus obras figuran: Filosofía biológica (1954); La razón y los remedios (1964); El catálogo de la vida (1970); Sobre las revoluciones verdes, Historia y Principios de la Agronomía (1973); Una epistemología del espacio concreto, Hacia una neo-geografía (1977); Filosofía de la imagen (1984); El dominio del viviente (1988); Rematerializar, Materias y materialismo (1989); La piel descubierta (1993); Por una filosofía de la enfermedad (1996); Desechos, detritus, lo abyecto; una filosofía ecológica (1997); Cambio de perspectiva, el adentro y el afuera (2002); La subjetividad (2004), entre muchas otras. Nota del editor.

1 Op. cit. loc. cit. Nota del traductor. 
que exceptuada la muerte — que casi solo es un mal por los preparativos de los que se la hace preceder- la mayor parte de nuestros males físicos son aún nuestra obra... Si los habitantes de esta gran ciudad (Lisboa) hubieran estado distribuidos más igualmente y más ampliamente alojados, los daños hubieran sido mucho menores o quizás nulos.

De este universo al que acusamos equivocadamente, sepamos más bien reconocer la estabilidad. Y en cuanto a las perturbaciones que sobrevienen -el mal llamado físico- digamos que obedecen a una necesidad. Es más: Elie de Beaumont se dedicó a hacer su inventario, a precisar las conmociones por venir, así como sus direcciones y sus emplazamientos. En efecto, el tectónico llega hasta dar cuenta de las arrugas, de las tuberosidades, de los empujes como de las fosas que los acompañan. Desde el momento en que la tierra se enfría, no puede dejar de plegarse.

El mal no reside tampoco en la vida o los vivientes; si ciertas especies se pelean entre ellas y dan el espectáculo de la violencia, a veces incluso de la crueldad, es porque defienden su territorio y aseguran su alimento; la guerra cesa desde que están saciadas. Por lo demás, si le creemos a Lorenz, los seres soportan mal el amontonamiento, la excesiva proximidad; por esto la combatividad misma de una fiera será inversamente proporcional a la distancia que lo separa de su lugar de habitación. La vida se las arreglaría pues para dispersar a los animales, y por ahí mismo aseguraría su alimento. También aquí, lo que se considera como miserable (la lucha sin cuartel entre las bestias) serviría, por el contrario, a sus intereses.

Que todos los vivientes deban morir, ¿no es la prueba de una maldición? Pero esta desaparición libera de individuos que se vuelven embarazosos; además, no desaparecen sino después de haber asegurado la propagación de la especie; y gracias a esta reproducción, esta vida misma se renueva; en caso contrario ella permanecería encerrada en lo mismo; el hecho de la desaparición constituye una poderosa ventaja, lo que equivale a la renovación o a la biodiversidad.

No nos detendremos en el caso del dolor que se añade al mal y lo amplifica; ¿no es el signo de un viviente desarreglado? Pero, en principio, el dolor nos alerta sobre nuestros disfuncionamientos; y cuando no tiene ese papel (de alguna manera la alarma sobrepasa, por el sufrimiento, lo que ella nos quiere indicar) lo consideramos como el inevitable efecto de nuestra sensibilidad que intensifica el menor trastorno. También acá, no apercibimos un "desarreglo" o un fracaso de la organización, sino lo que resulta de una constitución sólidamente dispuesta (y que comanda las partes y las armoniza).

Leibniz — campeón del optimismo, es verdad- no dudaba pues en ver en nuestro mundo actual el mejor de los posibles, el que forma el conjunto más rico 
y el mejor organizado, acá donde el más grande número de elementos han sido llamados a existir, todos tan activos. Obedece a dos grandes principios: el de plenitud (por esto, según La monadología, cada porción de la materia puede ser concebida como un jardín lleno de plantas, y como un estanque lleno de peces), pero también el de la economía: la mayor potencia con los menores medios.

Declaramos inocente la creación, pero ¿dónde se encuentra entonces "el mal verdadero"? Rousseau se imaginaba al hombre bueno; para él, era la sociedad la que lo depravaba. ¿En qué se fundamenta semejante dualidad que sirve para reforzar el movimiento antisocial y para favorecer un solipsismo peligroso?

Creemos descubrir, en la sola naturaleza del hombre, en su base misma, las raíces de lo que buscaremos combatir luego, puesto que la filosofía debe contribuir a tratar de disminuir, para no decir impedir, lo que consideramos como malhechor.

La duda no tiene ninguna posibilidad: el individuo no cesa de afirmarse -llega incluso a absolutizarse- - y no encuentra ni reposo ni contentamiento más que en la rebaja de los que lo rodean. Ya Kant lo subrayaba: "Hay en el infortunio de nuestros mejores amigos algo que no nos disgusta por entero"2. Asimismo, experimentamos rápidamente odio con respecto a nuestro benefactor, porque estamos demasiado subordinados a él y por lo mismo disminuidos; por otra parte -lo que muestra nuestra debilidad y nuestra incapacidad - lo que nos ha dado no lo hemos adquirido nosotros mismos. Necesitamos anular esta situación, perseguir con nuestro mal genio al que nos ha socorrido, y atacar, al menos, "su reputación".

La tendencia profunda del hombre lo empuja no tanto a perseverar en su ser como aaumentarlo por todos los medios; también se encuentra ella en el origen de las peores pasiones que van a envenenar la vida inter-individual, hasta llegar incluso a inquietar y desestabilizar la sociedad. Esta auto-afirmación - que consideramos como nuestro "pecado original", pues el solo hecho de ser puestos en el mundo nos condena a esta sorda violencia - se enraíza en la vitalidad, el querer-vivir ciego. Este habita a todos los seres, incluso a los vegetales que resisten a las peores privaciones (por ejemplo, las malas hierbas logran desarrollarse hasta en las piedras o en los intersticios que ellas cavan); tienen que ver pues con lo que no se deja desarraigar y enjambran a todo viento, en proporciones que confunden. Hemos indicado que el animal no conoce el frenesí que caracteriza al hombre; se satisface con lo que contenta sus necesidades, pero no deja de batirse para defender su territorio y colmar sus instintos (nutrirse y reproducirse).

2 Kant. La religión entre los límites de la mera razón. Madrid: Alianza, 1981. 
Pero el hombre sobrepasa a los seres de la naturaleza por su energía pulsional y sus posibilidades agresivas; él es el único que se proyecta en el porvenir y que se persuade que mañana podría faltar; por esto su rabia para captar, e incluso para acumular (la avidez, el atesoramiento, la posesividad). No ignora tampoco que la muerte lo espera, que lo destruirá (los vegetales como los animales lo ignoran), lo que agrava su finitud; por consiguiente, lucha contra esta muerte a través de la búsqueda de los honores y de las victorias (por lo demás irreales, con toda frecuencia) sobre las personas; busca todo lo que puede prolongarlo o lo que consagra su potencia (retarda así la hora de su desaparición).

Es el espinosismo el que nos parece haber tomado mejor conciencia de la vida humana y de sus aspectos "páticos"; el filósofo nos muestra sobre todo que solo debemos contar con una sola "pasión" de la que deriva todo lo demás: el deseo, a tal punto invasor que nosotros llamamos "bien" a lo que deseamos, y no a la inversa como lo cree un moralista crédulo (este se imagina que estamos atraídos hacia el bien; solo lo estamos icuando él responde a nuestro interés!).

El espinosismo no se ha limitado a esta remarcable concepción unitaria y radical; a partir de lo que considera lo fundamental, ha logrado deducir el conjunto de la vida afectiva de tal o cual; puede determinar con precisión lo que nos define en nuestras menores particularidades individuales.

Me propongo tratar de los vicios de los hombres y de sus enfermedades a la manera de los geómetras —escribe Spinoza, nuestro guía-... Trataré, pues, de la naturaleza de la Afecciones y de su fuerza, y del poder del Alma sobre las mismas, siguiendo el mismo Método del que me he servido en las partes anteriores... y consideraré las acciones y los apetitos humanos como si se tratase de líneas, de superficies y de cuerpos sólidos" (Prefacio a la tercera parte de la Ética: "sobre el origen y la naturaleza de las afecciones") ${ }^{3}$.

Con este filósofo se abre finalmente una psicología que no es ya descriptiva; esta, la habitual, empírica y rapsódica, solo tiene en cuenta algunas situaciones o algunas circunstancias, entre las más evidentes; entonces lo único que puede aportar es decepción en razón de su parcialidad, y también de su sumisión a un dato que solo puede observar, sin saberlo conectar con sus causas o, al menos, con lo que lo explicaría. Pero Spinoza va a desarrollar una antropología sistemática, deductiva incluso, susceptible, sin embargo, de llegar hasta lo concreto y de proveer su "razón de ser".

Convenimos en que es verdad que algunos teóricos casi se habían dado cuenta de este camino, como Hobbes que avanza en esta dirección. De ello resultaba para él "la guerra de todos contra todos". En efecto, cada uno de nosotros busca sacar ventaja. "Pues la naturaleza de los hombres es tal que,

3 Op. cit. Buenos Aires: Aguilar, 1969. pp. 172, 173. Nota del traductor. 
aunque puedan reconocer que muchos otros son más vivos, o más elocuentes, o más instruidos, difícilmente creerán, sin embargo, que haya muchos más sabios que ellos mismos: pues ven su propia inteligencia a mano, y la de otros hombres a distancia"4. De esta forma partiríamos, en este análisis, de una especie de desigualdad a causa de nuestra superioridad.

Otra fuente de enfrentamiento: "si dos hombres cualesquiera desean la misma cosa, que, sin embargo, no pueden ambos gozar, devienen enemigos; y en su camino hacia su fin (...) se esfuerzan mutuamente en destruirse y subyugarse" 5 .

Pero la demostración espinosista nos parece mejor asegurada, más completa y más rigurosa: del deseo fundamental, que se auto-afirma, va pronto a resultar "el amor y el odio", en el sentido en que amamos a aquel o aquella que nos reconoce y que nos da ventajas; inversamente, se concibe el nacimiento del odio o de la aversión con respecto a aquel o aquella que nos humilla, o solamente nos ignora. Es siempre claramente el ego el que se ramifica y se extiende; solo él comanda las pasiones.

Imaginemos que aquel o aquella que amamos se pone a manifestar interés con respecto a otro ser; se convertirá entonces sin falta en nuestro rival o nuestro enemigo, porque queremos todo para nosotros, exclusivamente. No tarda en estallar la violencia de los celos, pero también un conflicto nace en nosotros, pues vamos a "fluctuar" (amamos, pero odiamos al mismo tiempo a aquel o aquella que se desvía de nosotros y que comienza, en efecto, a desprenderse de nosotros). La ambivalencia, aquí manifiesta, no podrá durar; será preciso resolver la contradicción de una manera o de otra; vamos a dedicarnos a ello. Podrá ocurrir que terminemos por detestar a aquel o aquella que amábamos porque, finalmente, escogió el campo de los otros que probablemente nos disminuía; ahora bien, la afección amorosa solo debe confirmarnos en nuestra superioridad o al menos en nuestra originalidad (la exclusividad, la avidez, la voracidad pasional).

Todo va, además, a ampliarse y a encadenarse: ¿por qué experimentamos simpatía (un sentimiento súbito, inexplicable aparentemente) por un individuo que nos cruzamos? Podría ser que, por algún lado, él se parezca a aquel o a aquella que amamos (la menor similitud es suficiente); incluso llegamos a extenderla: requerimos solamente — para que él mismo sea apreciado-que, a su vez, revele alguna afinidad con aquel o aquella al que acabamos de juzgar positivamente. Por este camino se agranda el imperio del yo, todo ello derivado del sujeto y de su querer-vivir.

\footnotetext{
$4 \quad$ Hobbes. Leviatán. Madrid: Nacional, 1983. p. 222.

5 Ibídem.
} 
Mencionemos otra causa o factor de estima espontánea (un amor incipiens): supongamos que A - aquel o aquella al que amamos- esté a menudo acompañado de su amigo o amiga A'; este (o esta) merecen nuestra consideración: los amigos de nuestros amigos son nuestros amigos, según el conocido proverbio. Al comienzo, no teníamos ninguna razón para distinguir tal o cual ( $\left.A^{\prime}\right)$, pero él está asociado a aquel o aquella que nos confirma en nuestro ser. En el espinosismo, toda pasión se reconoce en su fluencia y en su ampliación; y nada puede entrabar esta locura pasional.

Lo que acabamos de mostrar "con respecto al amor" vale igualmente (en sentido contrario) para el odio; por lo demás, los dos no cesan de mezclarse y de convertirse el uno en el otro.

Otra extensión conforme a la lógica afectiva y a esta suerte de... mecánica de la irradiación: si alguien ha sido afectado por un sujeto que pertenece a una clase o a una nación diferente de la nuestra, no solamente amaremos u odiaremos a ese otro, sino también a todos los de su clase o de su nación; la intolerancia o el racismo provienen de acá (Proposición XLVI del libro III de la Ética ${ }^{6}$ ).

Previo al amor o al odio — que suponen los dos la existencia del otro- debemos encarar el caso de "el gozo y la tristeza" que no implica nada distinto a nosotros mismos. Ahora bien, estos sentimientos nos invaden según que creamos pasar a una perfección más grande o, por el contrario, a una menor. Estas dos pasiones se llaman adecuadamente "la alegría y la melancolía". Con la primera, tenemos la impresión de haber aumentado nuestro poder, mientras que en el caso opuesto, lo creemos reducido (el dolor existencial de la depreciación).

Estamos felices con la sola idea de nuestro ser, de su presencia, pero sobre todo de su soberanía (supuesta), así como de todo lo que podría reforzarla. Entonces nos enceguecemos nosotros mismos. Y no dejamos de paso de interpretar falsamente las conductas de nuestros semejantes; les asignamos infaliblemente bajos motivos con el fin de limitar sus méritos; al mismo tiempo, adornamos los nuestros lo más que podamos; llegamos hasta atribuirnos resultados mentirosos, con el fin de agrandarnos; por acá el amor propio y el contentamiento de sí mismos. Vanidad y orgullo se conciben: todo hombre cede a lo novelesco y deforma ventajosamente todo lo que le concierne (bordeamos lo alucinatorio).

Las cosas - por fuera de nosotros mismos y de los otros, todos plegados a la necesidad de confirmarnos - van a participar en nuestros dramas; van igualmente a regocijarnos o a herirnos. "Si alguno halla gozo en una cosa, la amaremos y desearemos hallar gozo en ella. Pero si imaginamos que el obstáculo para este gozo proviene de que otro haya sacado gozo en la cosa, nos esforzaremos en

$6 \quad$ Op. cit. p. 228. Nota del traductor. 
conseguir que no tenga más la posesión de ella"7. Se sigue el encarnizamiento por apoderarnos de lo que los otros "poseen". Aquí, sin embargo - a la inversa de lo que anunciábamos - no es tanto la cosa la que crea el conflicto y excita el deseo, como "el que la posee" (el "para sí" más que el "en sí"); pero difícilmente se separa la escasez de la propiedad, y la violencia del propietario.

Presentemos, sin embargo, una situación menos embrollada: aquel que recuerda un objeto, o una circunstancia que le está ligada, y que anteriormente le ha gustado, solo pensará en beneficiarse de ellos de nuevo, en lo posible, en el mismo contexto (la repetición); así nos encadenamos nosotros mismos; lo mismo no nos reserva ninguna sorpresa (por esto la seguridad) al mismo tiempo que nos regocijamos de nuestro dominio: "si se da cuenta de que falta alguna de esas circunstancias, el amante estará contristado" (Parte III, Corolario de la proposición XXXVI) ${ }^{8}$. A través de estos comportamientos centrados sobre los objetos, no abandonamos la esfera del ego que se auto-afirma e irradia.

A pesar de su método geométrico y deductivo, Spinoza evita las simplificaciones que nos hubiéramos podido temer. El filósofo se ha dedicado a evidenciar y a comentar "inversiones inesperadas" de su propia lógica, pero, en verdad, conformes a su punto de partida: el deseo invasor y polimorfo que cae en una perpetua ambivalencia.

Primera de estas inversiones: el odio se mantiene y se acrecienta seguramente por medio del odio, pero él podrá de súbito transformarse en su contrario, a la menor manifestación de un amor; en efecto, la crueldad o la simple aversión con respecto a alguien resulta de una decepción anterior o de un amor impedido; una tal detestación supone una "fijación", por tanto un apego (de tendencia negativa o destructora); se comprende que al menor signo todo pueda bascular: "El amor es tanto más grande —anota Spinoza— cuanto más el odio lo ha precedido"; las dos pasiones (que se juzgaban contrarias) no cesan de llamarse la una a la otra; la una no es nunca más que el reverso de la otra.

Otra inversión posible: la humillación que expresa nuestra propia debilidad debería necesariamente secretar en nosotros el veneno de la melancolía, si no el desespero (acentuamos nuestra finitud y nos arruinamos nosotros mismos), pero algunos logran mudar este odio de sí en motivo de superioridad (no me parezco a otros, satisfechos de ellos mismos y murados en el orgullo, sino en la vanidad). El sujeto encuentra secretas satisfacciones en el hecho de que no cae en el error sobre él mismo, o una valorización mentirosa de sí mismo (el narcisismo primario).

\footnotetext{
$7 \quad$ Ética. Libro III, demostración de la proposición XXXII. Op. cit. p. 212.

8 Ibíd. p. 217. Nota del traductor.
} 
Otra dialéctica hábil y que no tiene que ver con una deducción monolítica o lineal: quedamos sorprendidos por el hecho —y el filósofo va a comentarlo— que algunos individuos que nos superan por sus cualidades, o sus comportamientos o sus prestaciones no suscitan en nosotros ni envidia ni juicios despreciativos. Admitimos al que es eminente, y lo alabamos incluso. ¿Por qué, pues es sorprendente? Pero nos atrincheramos en nuestro círculo; de la misma manera que no le discutimos a los árboles su altura o la fuerza a los leones, asimismo, no nos cuesta nada reconocerles a algunos una superioridad que no nos amenaza. Sin embargo sigue siendo una manera indirecta y astuta de ponerla aparte (una especie de denegación).

Evoquemos todavía una situación incomprensible, si no contradictoria, y que parece desafiar esta psicología demostrativa: alguien nos ayuda y nos rodea; trabaja por nuestro éxito. ¿Cómo la indiferencia (la ingratitud), luego el odio, pueden advenir tan pronto? Ya lo hemos indicado, este reconocimiento firma nuestra dependencia; lo único que podemos hacer es rebelarnos y reivindicar para nosotros la victoria que otro estaría tentado (para gloriarse) a atribuirse. La lógica da cuenta de lo que parecía una excepción o un bache en los principios.

Hacemos nuestra la psicología espinosista, en razón de su rigor, de su coherencia, y también de su conformidad con una experiencia que ella termina por alcanzar y a la que aclara con una luz cruda. Ella responde a nuestro problema, puesto que nos indica dónde reside "el mal" (el deseo que no se somete a un orden que lo obligaría o lo restringiría), lo que desorganiza la existencia individual y llena la vida social de tropiezos como de querellas.

Pero los psicólogos no siempre han admitido los resultados de un análisis que juzgan demasiado sistemático (construido en efecto, a golpes de teoremas). Le han opuesto otros desarrollos, y han recurrido a fundamentos diferentes. Pero nosotros querríamos mostrar (e incluso demostrar) que estos psicólogos retomaban el espinosismo mientras creían estarlo girando, o desbordándolo o ignorándolo.

Por ejemplo Gabriel Tarde -al que le acreditamos una psicología particularmente sugestiva - vio en la imitación lo que permite explicar la conducta de los hombres; estos no dejan de acercarse puesto que se copian los unos a los otros.

Nos apresuramos a reconocer en esta teoría anotaciones tan nuevas, como juiciosas; dan colorido a su "principio de base". Ante todo, este remite a toda una filosofía subyacente y unitaria; en física también juega este principio y se llamará la ondulación (una corriente inmaterial que atraviesa los medios); en biología se convertirá en la herencia, mientras que en psicología funciona la repetición y la 
sumisión a un modelo irresistible que reproducimos. El propio animal no escapa de él: el jefe del rebaño da el ejemplo y será siempre seguido por la manada o la piara o la banda. Este concepto de imitación —obtenido por un micro-análisis de lo ínfimo- eximirá a Tarde de referirse a lo que imponía una "sociología masiva", que se limitaba a explicar "la cosa por la cosa", en el sentido en que fabricaba entidades — un dispositivo de naturaleza tautológica — con el fin de dar cuenta de nuestros comportamientos (por ejemplo, la criminalidad por una tasa fija de ella, inherente a una colectividad). "No tenemos ninguna necesidad de esa concepción misteriosa de un espíritu colectivo, una consciencia social en nosotros que existiría por fuera y por encima de nosotros"9.

Esta imitación opera de manera automática, a menudo sin nosotros saberlo; Tarde no deja de aproximarla a la hipnosis, a tal punto estamos sometida a ella. Este extraño sonambulismo, o esta especie de contagio se desarrollan particularmente en las sociedades modernas; Tarde responsabiliza primero, al comienzo, a "la conversación", luego al libro, finalmente al periódico que va a intensificar la corriente alucinógena (la propagación de una "onda en un medio particularmente permeable").

Antes que la imprenta disemine lo que nos agarrará, "la conversación" define el primer centro de emisión; ella supone al menos dos personas que intercambian afirmaciones llamadas a difundir (los flujos). Por lo demás, según Tarde,

[...] se reserva en las casas habitadas por la clase superior una habitación consagrada a la charla, una sala de estar [...] Entre los griegos, los gimnasios comprendían entre sus dependencias, un sector cubierto o no, llamado exedro, donde los filósofos se reunían y que les servía de círculo [... Los patricios romanos, bajo el Imperio, tenían en sus ricas estancias, al lado de las triclinia y de las bibliotecas, una galería llamada también exedro [...] El origen de nuestros salones modernos es diferente; no proceden del locutorio de los monasterios puesto que este respondía a una necesidad de otra naturaleza: la de exceptuar alguna parte, una excepción necesaria a la regla monástica del silencio ${ }^{10}$.

La renuncia a toda conversación prueba aquí, de manera indirecta, hasta qué punto la necesidad de hablar es irresistible. Conocemos su función: confeccionar y renovar la opinión, diseminar lo que todos adoptarán.

Tarde mostrará sobre todo cómo, más tarde, la construcción de caminos y el desarrollo de los "correos" permitirán la emergencia de un medio de difusión sin igual, el "periódico" con sus impulsos irresistibles. "La evolución del Poder se explica por la evolución de la opinión, que se explica ella misma por la evolución de la conversación, que se explica a su turno por la serie de sus diferentes

$9 \quad$ Tarde. L'opinion et la foule. París: Alcan, 1901, Preámbulo.

$10 \quad$ Ibíd. p. 111. 
fuentes: enseñanza de la familia, escuela, aprendizaje, predicación, discursos políticos, libros, diarios"11.

La imitación obedece —-según Tarde-a dos leyes fundamentales: ante todo ella va (contrariamente a las apariencias o a las ideas recibidas) de adentro hacia fuera, ab interioribus ad exteriora; por ejemplo, en el siglo XV los franceses se inspiran claramente de los italianos, y en el siglo XVI de los españoles, pero, en los dos casos, antes de impregnarse de sus vestimentas, de sus modas, e incluso de su lenguaje, se habían prendado de sus bellas artes, de su literatura y de sus ideas, que los habían subyugado. E Italia misma imitó la Antigüedad greco-romana (sus estatuas, su retórica, los fundamentos de su vida política) porque ya sus artistas, sus oradores, sus escritores, se habían convertido al neo-paganismo; la propagación religiosa de los dogmas se le adelanta a la de los ritos o a la de las ceremonias. Y todo comienza por la confianza y la admiración. La corriente va de adentro hacia fuera.

Segunda ley de la fuerza casi epidémica: desciende de lo superior a lo inferior; este último no deja de copiar a aquel y de retomarlo. No puede resistir a la corriente que se ejerce sobre él y lo empuja iquiéralo o no lo quiera! Malebranche ya señalaba "la fuerte impresión que llevan a cabo en los espíritus débiles y en los tiernos y delicados cerebros, las personas de fuerte imaginación". Tarde va más lejos; según él, la ola nos arrastra a todos, sin excepción. Lo nuevo o lo original atraen; nos apresuramos a adoptarlo, con el fin de no estacionarnos en lo caduco (lo pasado de moda). Si a veces se nota lo inverso de la ley precedente - un conquistador que aprende del vencido- (como los francos en Galia), es muy simplemente porque aquel reconoció su superioridad social; la irradiación se opera siempre en el mismo sentido, de lo más o de lo mejor hacia lo menos, por ejemplo, la Corte; la élite de la aristocracia es retomada en los castillos, después en las estancias de la burguesía; por lo mismo el acento de la capital se difunde en las provincias y termina en el menor de los poblados.

Estaríamos tentados a añadir una tercera ley para calificar esta psicofísica, a saber: que el principio contagioso desciende poco a poco en los movimientos y las actitudes corporales (una lenta e irresistible somatización), como por ejemplo, la tendencia a caminar con el mismo paso y de la misma manera. "Se ha probado - por medio de mediciones delicadas - que en una misma ciudad, todo el mundo camina en promedio con una misma rapidez. En cuanto a los gestos y maneras (mucho más rápidamente aún que las particularidades de la locomoción), ellos se transmiten a las personas habituadas a vivir juntas y sirven para caracterizarlas" ${ }^{12}$. La epidemia ataca primero que todo los sentido

\footnotetext{
11 Tarde. Op. cit., p. 134.

12 Les lois de l'imitation. p. 212. 
superiores, antes de afectar los inferiores (por ejemplo, la pronunciación, los acentos, para no hablar de los bostezos; el de aburrición se comunica —según Tarde- más claramente que el estornudo o que la tos).

Es lo nuevo lo que más excita el deseo de conocerlo y de participar en él; la propagación se opera a toda marcha y nada puede lentificarla; el caso más frecuente quiere que si un bienandante, por la calle, se detiene y parece ver algo desconocido, inmediatamente todos se reúnen para asistir al espectáculo; asimismo, los alumnos se ponen a hablar como su maestro (vocalmente, en la entonación, el acento y también los mismos términos). Nos vestimos, nos divertimos todos de la misma forma en un medio en un período dado; por todos lados se instala la uniformidad.

En el origen: es, sin embargo, necesario admitir un foco de donde parte la irradiación; y esta ya no puede tener que ver con la simple recuperación, puesto que está en el comienzo; él es el casi "ex nihilo", la creación. Sin embargo, Tarde supo mostrar cómo lo que consideramos "el origen y lo original", en realidad, mezcla corrientes anteriores que de ese modo se reorganizan o se combinan entre sí: "Toda invención es un cruce afortunado, en un cerebro inteligente, de una corriente de imitación, sea con otra corriente de imitación que la refuerce, sea con una percepción exterior intensa, que hace aparecer, bajo un día imprevisto, una idea recibida [...]"13. No es la invención la que está en la base de la imitación, sino a la inversa, puesto que esta supone todavía los flujos anteriores.

Cada quien será atraído por el lado concreto y demostrativo de esta psicología inseparable de una filosofía más general de la naturaleza (las irradiaciones, las propagaciones que hipnotizan), pero nos parece que ella se limita a ilustrar al espinosismo al que reactualiza a su manera. Llegaríamos hasta sostener que lo imita.

En efecto, el deseo del individuo, en lo más profundo, tiende a reducir la distancia que lo separa de su modelo (juzgado superior). Lo anula y, en lo posible, busca sobrepasarlo. En estas condiciones, la imitación debe ser considerada no como un proceso primordial sino como aquel por el cual el ego omnipotente borra lo que lo inferiorizaba. Acapara para sí mismo lo que va a salvarlo de la marginalidad, o lo que lo desclasaba. Tarde se habría detenido a mitad de camino: él autonomiza una fuerza que atraviesa a los individuos, cuando se trata de la estrategia del ego que se rebela. Por otra parte, al que yo imito, lo desvalorizo; por una parte, logro apoderarme de lo que lo caracterizaba; por otra parte, no dejo de acentuar algunas particularidades (nos orientamos hacia la caricatura); también el modelo es bajado de su pedestal.

13 Les lois de l'imitation. París: Kimé, 1993. p. 47. 
Por lo demás, las dos leyes que Tarde enuncia se explican mejor de esta manera: siempre es lo inferior lo que capta en su provecho aquello de lo que lo superior se prevalía y que va a perder. Asimismo, el contagio no consiste en copiar sobre sí algunos aspectos superficiales; él se apodera de lo más profundo porque busca una completa y real inversión. Una simple transferencia, una propagación no es suficiente; debemos ir hasta lo más interior con el fin de desalojar al amo de su superioridad.

Corriendo el riesgo de caer en la simplificación, creemos que todas las elaboraciones psicologizantes confirman o redescubren la teoría espinosista; la concepción psicoanalítica no escapa de ello. Si estudia el desarrollo o la construcción del sujeto -la génesis - igualmente ilumina la potencia y la afirmación del yo; entra en la dinámica del deseo que hemos expuesto.

No le negamos algunas originalidades que es menester reconocerle al freudismo: supo especialmente resucitar lo que ya se ha hundido en nosotros, a tal punto los conflictos esenciales son reveladores y ganan, por consiguiente, enmascarándose (en caso contrario estaríamos expuestos y más aún fragilizados). Por la astucia de naturaleza óptica, el psicoanalista logra sacar lo inconsciente (aparente) de su sombra. La profundidad se vuelve visible y aflora, en la medida en que la relación entre el analista y el analizado reproduce la que el neurótico anudó con su entorno familiar y primero. El drama que desestabiliza al sujeto y que le es desconocido (debido a su represión) se vuelve poco a poco accesible a la observación del psicoanalista, a la vez que reintegrable por parte del paciente, que se salva de una escisión que él mismo había organizado y aceptado.

Pero ¿qué es lo que descubrimos, en las estructuras neurógenas fuertemente sedimentadas, si no el imperialismo del deseo y sus fracasos? Es verdad que toman muchas formas, aunque podamos fácilmente reagruparlas y unificarlas.

Primer drama, casi insoluble: la simple relación de la madre con su hijo abre a una situación envenenada. Para la madre, su hijo le pertenece (la dependencia, en tanto que él viene de ella que lo engendró; en el límite, uno y otra no pueden separarse; los dos sueñan con reencontrar el pasado fusional). Pero si esta madre se pone a ceder a las exigencias que pronto van a manifestarse por parte de aquel sobre el cual ella ejerce el cuidado y la educación, este comienza a escapársele y a imponerse; ella sufre con esto y también orienta ya a este niño hacia reacciones de omnipotencia y de viva insubordinación. Pero si ella rechaza sus manifestaciones de independencia y lo pliega a sus voluntades, él se sume en la sumisión, no sin mantener un sentimiento de rebelión, y muy probablemente de culpabilidad latente. 
Por lo demás, la lógica del deseo se ejerce aquí como en ninguna otra parte, a tal punto la afirmación del uno entraña la negación (o al menos la atenuación) de la otra, lo que va a colorear toda la intersubjetividad por venir (sea la dominación, sea la borradura). Lo más a menudo, la madre afectuosa exige que el niño sepa esperar (ella no lo obliga a renunciar a la violencia que significa, sin embargo, la separación y la futura ruptura) y que él retarde al menos el momento de la satisfacción; pero esto no disminuye en nada la renuncia y la obediencia.

La salida de estos enfrentamientos podría conducir al auto-castigo "al insumiso que ha sido vencido", pero una tal agresividad contra sí mismo no significa que tendamos al aniquilamiento o a la extinción de sí mismo (el deseo solo se conoce a sí y sus ramificaciones). Por el contrario, es la única vía dejada al niño para merecer el amor de su madre, el que él busca captar. Lo que corremos el riesgo de apercibir como "negativo" (la retención de la demanda o el rechazo de lo pulsional) debe ser comprendido como el reverso hábil de un recorrido positivo: el apego a aquella de la que se depende. Al final, ya no sabemos quién aprisiona al otro.

Es patente que descartamos las consideraciones naturalistas, como si la libido debiera atravesar ciertas fases obligadas (los estadios), mientras que todo deriva - según nosotros - de la primera batalla cuya salida va a pesar sobre el psiquismo (grosso modo: o bien la reivindicación insaciable o bien la frustración culpabilizadora). La relación de poder contamina, o más bien orienta, la existencia del niño.

Segundo episodio desestructurante: el niño nace en una familia; va a tener que admitir que se beneficia — pero al igual que otros — del tiempo, de los cuidados (libidinosos) y del afecto de su madre; pero él no es el único; el padre le roba la madre, la que él no puede acaparar para sí mismo. Por lo demás ¿cómo podría él comprender que el amor pueda repartirse sin disminuir? Y por esto surge el odio de esta expoliación.

En presencia de lo insoportable, los psicoanalistas no han dejado de observar aquí la frecuencia de las conductas regresivas; a falta de poder aceptarlo, el niño echa para atrás (el tartamudeo, la enuresis, el sonambulismo). No veamos acá lo contingente (lo que ocurre) sino una estrategia de guerra. El Edipo se enfrenta a la autoridad y va a inspirar numerosas réplicas; solo consideremos la siguiente: el niño se identifica con la figura que él reprueba, con el fin de anularla de este modo (es una técnica frecuente y victoriosa disponer dentro de sí mismo lo que se busca destruir).

Pero sobre todo el niño corre el riesgo de llegar a una familia que ya cuenta con mayores, o incluso podría tener que acomodarse al nacimiento de un her- 
mano o de una hermana. ¿Cómo no iban a estallar los celos? Responde a esta presencia con un odio inevitable. Y si termina por prendarse de este hermano menor, si lo abraza, es como una manera de ahogarlo. De una manera o de otra, conviene humillar a quien ha arrebatado lo que nos estaba reservado en el seno de la familia (por esto el complejo de Caín, el que mató a su hermano Abel).

Tenemos acá un escenario clásico de la venganza, uno entre otros: el mayor, desposeído y afligido, brilla en las tareas escolares, a tal punto comprendió que por ese sesgo recuperaba el afecto de sus padres; logra rebajar a su hermano que va a deslizarse hacia una existencia fácil (el dejar pasar, la indolencia); este sabe por adelantado que es incapaz de tales proezas, no puede aceptar el desafío, y por ese motivo, carece de la motivación que anima al mayor victorioso. También se ve lo inverso (pero una tal inversión siempre obedece, a pesar de las apariencias, a la misma guerra); en efecto, este hermano mayor - traumatizado después de haber sido desposeído del bien, con el que pensaba que era para él solo- no logra liquidar su pasado, mientras que su hermano pequeño, más libre, menos atestado (pues llega a un universo ya ocupado por otros, con los cuales es preciso contar), se vuelve excelente, allí donde su hermano registra un segundo fracaso; y este hermano mayor lo acepta tanto mejor cuanto que está culpabilizado y acostumbrado al despojamiento afectivo; él espera otros abandonos.

Los hermanos nacen pues enemigos, porque el hombre solo puede vivir si aumenta su potencia y extiende su reino (la lógica espinosista o la ley destructora del deseo).

Tercer drama que queremos evocar a grandes rasgos: la sociedad no ha podido ni ha sabido proteger la igualdad de sus miembros; por consiguiente, algunos no dejan de disminuir a los que los rodean; la guerra enreda las relaciones y las envenena. Es así como les da ventaja a los varones (los hombres) e inferioriza a las niñas, después de haber sostenido probablemente lo inverso (el matriarcado). El derecho e incluso la religión refuerzan la dualidad cultural.

Como este antagonismo reposa sobre nada, para poderse legitimar (ilusoriamente), se "somatiza" y cuenta con argumentos anatómicos (sin apelación). De repente, el niño macho teme, en sus fantasmas, ser castigado, castrado, mutilado, a la menor salida; el órgano que posee (y del que obtiene alguna vanidad) le será quitado, si no se somete a la disciplina - mientras que la niña se imagina haber nacido incompleta-; también ella sueña con ser o con volverse un muchacho (el complejo de Diana la cazadora). La libido (el querer vivir) ha logrado hábilmente cavar una distancia entre los unos y las otras, a partir de una base orgánica: los atributos de la virilidad fetichizados. Una diferencia ha sido transformada en oposición, luego en desfase (la carencia); posteriormente, 
la distancia no cesará de mantenerse e incluso de ampliarse. No excluimos que el acto sexual, o el matrimonio, corresponda a una respuesta de la mujer que recupera al hombre e incorpora en ella aquello de lo que él se gloriaba.

Será fácil notar, sin embargo, que el desfase corresponde a realidades, los récords y las actuaciones de los unos, cuando las otras (desenganchadas) no pueden obtener éxito tan bien, o incluso rehúsan la competencia (física o intelectual); una interpretación naturalista o casi constitucionalista, que remite ella misma a la biología (la energía de los unos, la debilidad de las otras).

Por ahí, el observador olvida que la motivación y la creencia (la superioridad imaginaria) son suficientes para estimular o, inversamente, para desanimar. Siempre realizamos solo lo que se espera de nosotros.

Edipo, Caín, Diana, en los tres casos (para atenernos a las situaciones conflictivas primarias), asistimos a la misma competencia (la avidez): el uno tiende a envilecer al otro y a imponérsele. Ahora bien, la psicología espinosista había tomado nota de esta "destructividad"; ella había dado cuenta por la lógica de un ser que, amenazado por la muerte, busca vencerla y comienza por romper su competencia, con el fin de convencerse de su omnipotencia y de que todo lo acapara.

Se nos podría oponer que el freudismo, cuando menos, supo reconocer el campo del inconsciente, del que Spinoza no pronuncia palabra; para este último funciona a cielo abierto la mecánica existencial afectiva. Según Freud, interiorizamos nuestros problemas. Pero si los reprimimos y los somatizamos es porque así los intensificamos.

No estamos dispuestos a admitir este corte en el hombre, entre lo que él dominaría por un lado, y por el otro, lo que se le escaparía (por lo demás, los filósofos lo han subrayado: para poder asegurar un tal alejamiento, es necesario seleccionar y por tanto conocer bien lo que descartamos y reprimimos; importa "conocerlo suficiente icomo para jugar a que no se lo conoce!"). En todo caso, para nosotros, el inconsciente pretendido no logra la operación de hundimiento que algunos le prestan; debemos observar el constante "regreso de lo reprimido". El inconsciente pertenece a la exterioridad; él no está adentro sino afuera; se expone, pero, sin duda, por numerosas razones, preferimos no apercibirlo y jugar a la ceguera.

Nadie negará, sin embargo, la importancia que toma para los individuos el hecho de entrar en los más diversos reagrupamientos, donde se encuentran verdaderas satisfacciones. ¿Esto no marca el fracaso del análisis (negro) de Spi- 
noza? En la sociabilidad beneficiaria cesan entonces toda violencia, o incluso las prebendas a corto término; el amor desenfrenado de sí mismo conoce a la vez un límite, e incluso su cesación. Entramos en conjuntos humanizados y positivos.

Cada uno de nosotros participa al menos de la unidad nacional que arrastra gustos y actitudes comunes; nos acurrucamos los unos contra los otros; lejos de proseguir nuestras querellas, nos asociamos y defendemos nuestra pertenencia a la misma patria. El propio Kant debía notarlo: el hombre va a encontrar en "la sociedad civil" la seguridad y, sin duda, también la prosperidad, todo lo que iba a combatir su individualismo. Este último es incluso indispensable; en efecto, la discordia se revela tan nociva que ganamos renunciando a ella. Salimos de la guerra y de la indisciplina que nos arruinaba.

Así como los árboles de un bosque —escribe Kant—, precisamente porque cada uno trata de quitarle el aire y el sol al otro, se esfuerzan por sobrepasarse, alcanzando de ese modo un bello y recto crecimiento, mientras que los que están en libertad y separados de los demás extienden las ramas caprichosamente, creciendo de modo atrofiado, torcido y encorvado, del mismo modo la totalidad de la cultura y del arte que adornan la humanidad, tanto como el más bello orden social, son frutos de la insociabilidad ${ }^{14}$.

Entonces, no permanezcamos en la libido o en la tendencia fundamental a aumentar su ser, puesto que debemos abandonar este estado demasiado dispendioso y, en el límite, insostenible.

Por lo demás, las guerras intestinas se acaban por sí mismas; pueden corresponder a situaciones de acá en adelante caducas. Antaño, según Kant, el pastor (la vida pastoral) y el agricultor (el labrador) no cesaban de oponerse. "Al labrador le resultaba muy fastidiosa la vecindad del pastor, porque el animal que pasta no se cuida de las plantaciones. Después de haberlas dañado, al pastor le era fácil alejarse con su rebaño y sustraerse a cualquier indemnización, puesto que por detrás de sí no dejaba nada"15. Es claro que los famosos "encerramientos" (la barrera de los campos) le ponen fin a este enfrentamiento.

La mayor parte de los filósofos fueron más lejos; reconocen, en el fondo del hombre, no la violencia de la afirmación sino una tendencia a la simpatía por sus semejantes, asimismo como las naciones estarían llevadas hacia alianzas que asegurarían la paz (el abate de San-Pierre debía incluso elaborar un Proyecto de Paz perpetua y proponer a todos los pueblos de Europa una constitución que garantizaría la integridad territorial de cada uno; el Fœdus Amphictyonum nos liberará de las miserias de la guerra).

14 Kant. Filosofía de la historia. "Idea de una historia universal". Buenos Aires: Nova, 1964. p. 46. 
Uno de los filósofos, entre los más pesimistas, Schopenhauer, debía insistir sobre la potencia del sentimiento de piedad, que atenaza al hombre en presencia de la aflicción de su semejante; sería empujado a reconfortarlo; aquí el egoísmo sería destruido - a través de la compasión-, en tanto renunciáramos al mantenimiento de las individualidades y a su separación asesina.

Sin llegar hasta allá, los moralistas se han contentado con recurrir al interés (especialmente Bentham; el utilitarismo) y al cálculo; el altruismo resulta de ello; se revela tan ventajoso que no ganamos nada prolongando o manteniendo la hostilidad; el hombre lo concibe directamente; en estas condiciones, prefiere los acuerdos y la asociación. La naturaleza no quiere las estériles y costosas batallas. La psicología espinosista no habría apercibido más que el anverso de la realidad, es decir (para retomar la respuesta kantiana), una primera asociabilidad que remata en una verdadera sociabilidad.

No estamos convencidos por este cambio de perspectiva; ¿cómo negarlo?; la entrada en una sociedad, fundamentada sobre ventajas comunes y reales, solamente desplazó (y no suprimió) el problema antagonístico; lo ha elevado un grado, en el sentido en que la guerra - en lugar de golpear y de concernir a los sujetos- toca de acá en adelante a los pueblos. El mal y la desgracia se han extendido. Y la paz entre las naciones define una suave ensoñación (la del abate Saint-Pierre): la historia se encargó pronto de ratificar este juicio.

En suma, cada nación solo piensa en aplastar, o en disminuir o en integrar a su vecina (su rival, la vecina es frecuentemente el enemigo por el hecho de la proximidad que, a su vez, favorece la tentación de anexión). El espinosismo, primero centrado sobre la afectividad individual, se ha ampliado de alguna manera, se ha intensificado también, puesto que de ahora en adelante también tiene que ver con los conjuntos. Kant creyó que con el Estado republicano sería el poder legislativo el que decidiría o no entrar en el conflicto armado; la respuesta entonces sería dada por la voluntad popular que no dejaría de impedirlo.

No puede por menos de ser necesario el consentimiento de los ciudadanos para declarar la guerra. Nada más natural, por tanto, que ya que ellos han de sufrir los males de la guerra, como son los combates (...) lo piensen mucho y vacilen antes de decidirse a tan arriesgado juego ${ }^{16}$.

El filósofo finge olvidar que los pueblos desearán participar en la tragedia de la potencia que los salva de la monotonía de la vida ordinaria, y que les permitirá —en caso de victoria - un excedente de dominación; ya no es solamente el ego el que triunfa, es el yo colectivo. Por lo demás, Kant —él mismo bastante oscilante- reconoce los méritos o los recursos que los pueblos les deben a la codicia,

16 Kant. La paz perpetua. Madrid: Espasa-Calpe, 1972. pp. 103-104. 
a la ambición, al apetito insaciable de posesión (completamente opuestos a los hombres suaves como corderos, ellos practican pues la rivalidad y la discordia).

Finalmente, pensamos haber localizado y definido el "mal" que habremos de enfrentar, luego: ¿cómo luchar como filósofo contra un tal imperialismo, el de un sujeto que ha encontrado el medio de aumentar su fuerza fundamentándose en un grupo que le procura satisfacciones más intensas (a prorrata de su volumen) y lo colma por su extensión? Además, la nación pone en funcionamiento medios que superan las capacidades individuales.

La llegada de las antropologías fusionales (el sujeto que se asocia a otros para formar unidades más temibles) no cuestiona nuestro punto de partida; se trata, por medio de esta maniobra, no de sugerir otra concepción de la naturaleza humana, sino de mostrarnos cómo el yo se fortifica, se aumenta aún, y logra imponerse. 